УДК 621. 315. 592

DOI: https://doi.org/10.36910/6775-2313-5352-2019-14-16

Мирончук Д.Б., студент., Кот Ю.О., студент, Мирончук Г.Л. к.ф.м.н., доц., Замуруєва О.В., к.ф.-М.Н.

Східноєвропейський національний університет імені Лесі Українки

\title{
ВПЛИВ РОЗМІРІВ ЗЕРЕН КРИСТАЛІЧНОГО ПОРОШКУ НА ІНТЕНСИВНІСТЬ ГЕНЕРАЦІЇ ДРУГОЇ ГАРМОНІКИ
}

У даній роботі проведено аналіз впливу ширини забороненої зони та середніх розмірів зерен на інтенсивність генерації другої гармоніки кристалів $\mathrm{AgGaGeS} \mathrm{s}_{4}$ ma $\mathrm{AgGaGe} \mathrm{Se}_{8}$. Отриманий результат свідчить про те, що багатокомпонентні халькогеніди, а саме $\mathrm{AgGaGeS} \mathrm{ma}_{4} \mathrm{AgGaGe} \mathrm{Se}_{8}$, є перспективними нелінійно-оптичними матеріалами, оскільки в них поріг лазерного пошкодження є більшим, а нелінійно-оптичний відгук порівняний із комериійно використовуваними $\mathrm{AgGaS} 2$ ma AgGaSe2.

Ключові слова: нелінійна оптика, лазер, генерація третьої гармоніки.

Постановка проблеми. Перетворення частоти ІЧ лазерних джерел (частотна модуляція) $є$ одним 3 основних завдань оптоелектронної техніки, яку використовують у цивільній і військових галузях, охоплюючи атмосферний моніторинг, лазерний радар та ін. Явище генерації другої гармоніки в кристалічних порошках вперше спостерігали в 1968p. Рез 3 співробітниками [1], а потім детально досліджували Грая [2] і Куртц та Перрі [3]. Цей метод полягає в наступному. Кристали, які мають напрям фазового синхронізму, проявляють лінійну залежність інтенсивності генерації другої гармоніки від середніх розмірів зерен, якщо ці розміри менші когерентної довжини. В більш крупних зернах інтенсивність генерації другої гармоніки не залежить від їх розмірів. Грая використовував цей метод для оцінки когерентної довжини. В кристалах, які не мають напрямку фазового синхронізму, інтенсивність генерації другої гармоніки не залежить від розміру зерен. За нахилом прямої, яка апроксимує залежність інтенсивності генерації другої гармоніки від діаметра зерен можна розрахувати середнє значення елементів тензора нелінійної сприйнятливості [3]. Існує також можливість визначення кута анізотропії кристалу [2] і пов’язаного з ним ширини головного максимуму в кутовому розподілі інтенсивності ГДГ. Куртц і Перрі [3] запропонували застосовувати порошковий метод для класифікації нелінійних кристалів, які використовуються в лазерній оптиці. Нині цей метод інтенсивно використовується для вивчення нелінійно-оптичних властивостей нових матеріалів [4-6].

Аналіз останніх досліджень і публікацій. Із 1970-х років у якості нелінійно-оптичних матеріалів практично використовуються $\mathrm{AgGaQ}_{2}(\mathrm{Q}=\mathrm{S}, \mathrm{Se})$ [7] та $\mathrm{ZnGeP}_{2}$ [8]. Проте всім цим кристалам властиві ті чи ті серйозні недоліки. Наприклад, кристали $\mathrm{AgGaQ}_{2}(\mathrm{Q}=\mathrm{S}, \mathrm{Se})$ мають низький поріг лазерного пошкодження, а $\mathrm{ZnGeP}_{2}$ демонструє сильне двофотонне поглинання звичайного 1 мкм (Nd: YAG) або 1,55 мкм (Yb: YAG) джерела лазерного накачування. Тому пошук нових НЛО матеріалів $є$ актуальним і останнім часом дуже активним [4-6]. Серед усіх вимог, що ставлять до нових ІЧ нелінійно-оптичних матеріалів, одними 3 найвагоміших $\epsilon$ збільшення порогу лазерного пошкодження (стійкості) та уникнення двофотонного поглинання.

Виділення невирішеної проблеми. Збільшення променевої стійкості в нелінійних кристалах зазвичай пов'язують зі збільшенням ширини забороненої зони сполук. Останнім часом багато досліджень зосереджені на включенні в ІЧ НЛО кристали нелінійно-оптичних активних одиниць, а саме тетраедрів $(\mathrm{Ga} / \mathrm{Ge}) \mathrm{Q}_{4}(\mathrm{Q}=\mathrm{S}, \mathrm{Se})$, що містять халькогени [9]. Введення лужних або лужноземельних металів дозволяє збільшити ширину забороненої зони, а щільне розташування мікроскопічних НЛО активних блоків збільшує можливість досягнення великої макроскопічної нелінійно-оптичної відповіді.

Результати дослідження. Вимірювання проводили за допомогою установки, представленої на рис. 1. У досліді використовували Nd:YAG наносекундний імпульсний лазер 3 довжиною хвилі 1064 нм як джерело фундаментального випромінювання. Значення енергії плавно змінювали поляризатором Глана. Значення падаючого фундаментального випромінювання вимірювали за допомогою германієвого детектора, а його другу гармоніку - за допомогою фотопомножувача 3 встановленим інтерференційним фільтром, що пропускає електромагнітне випромінювання з довжиною хвилі 532 нм (друга гармоніка).

(C) Мирончук Д.Б., студент., Кот Ю.О., студент, Мирончук Г.Л. к.ф.м.н., доц., Замуруєва

$$
\text { O.В., к.ф.-м.н. }
$$




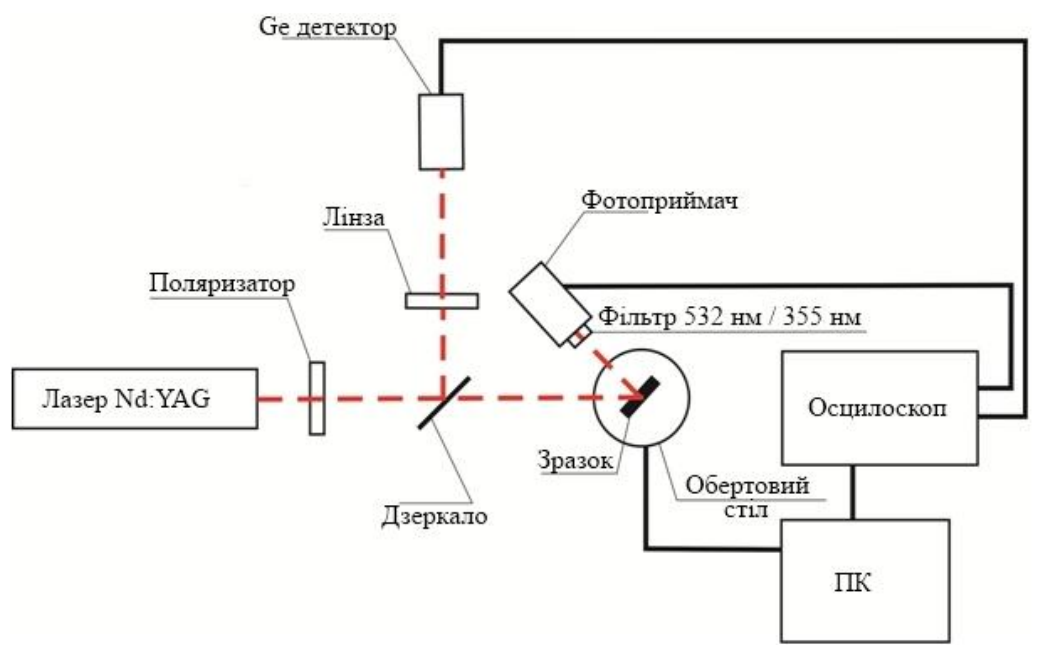

Рис.1. Вимірювальна система для визначення інтенсивності сигналу другої або третьої гармоніки залежно від застосовуваних фільтрів в результаті опромінення лазерним світлом 3 довжиною хвилі 1064 нм

Зразки поміщали на оборотний стіл у спеціальний тримач. Рівні інтенсивності отриманих сигналів основного випромінювання i його другої гармоніки зчитували за допомогою осцилографа Tektronix із частотою 1 ГГц. Таким чином фіксувалась залежність генерації гармонік від інтенсивності фундаментального сигналу.

Вимірювання ГДГ виконували за допомогою методики порошку Куртца-Перрі [3]. Потрібно зазначити, що метод Куртца-Перрі дозволяє давати лише відносну оцінку ефективності нелінійно-оптичних перетворень, використовуючи лише порошок нелінійнооптичного кристалу. Цей метод дає можливість досліджувати нові перспективні НЛО матеріали, проте в ньому використовуємо наступні наближення - частинки порошку вважаються монокристалами з близькими розмірами до 100 мкм, які хаотично орієнтовані в просторі. Водночас кристаліти рівномірно розподілені між пластинками. Розмір зерен у порошку, що отримані внаслідок механічного дроблення, оцінювали за допомогою оптичного мікроскопа. Вони становили 30-100 мкм. Результати вимірювання ГДГ для досліджуваних зразків представлені на рис.2.
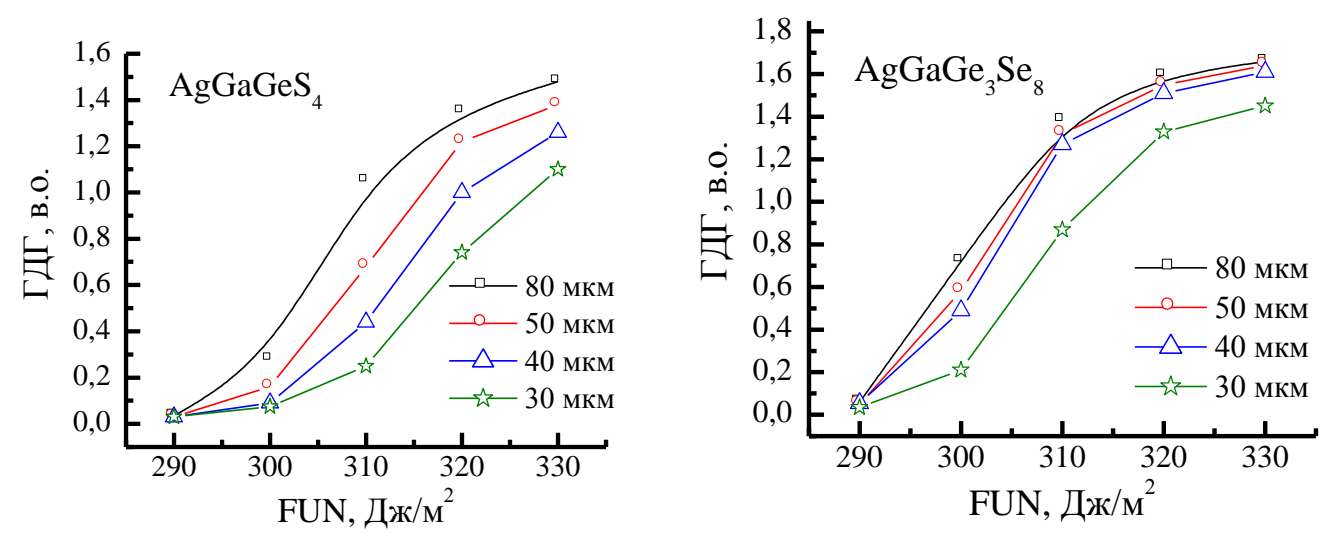

Рис.2. Залежність інтенсивності генерації другої гармоніки від густини енергії падаючого фундаментального пучка.

Результати досліджень ГДГ у кристалі $\mathrm{AgGaGe}_{3} \mathrm{Se}_{8}$ показують, що нелінійно-оптичний коефіцієнт виміряний методом Куртца-Перрі становить 29,3 пм/В, що є дуже близьким до $d_{36}$ $\mathrm{AgGaSe}_{2}$ (30 пм/B) [10]. Отриманий результат добре узгоджений з даними роботи [11], у яких зазначено, що коефіцієнт $d_{31}$ для сполуки $\mathrm{AgGaGe}_{3} \mathrm{Se}_{8}$ становить $\sim 29$ пм/В. Значення $d_{36}$ для $\mathrm{AgGaS}_{2}$ у наукових роботах змінюється майже в три рази [12], що пояснюється проявом неконтрольованої дефектності. Вперше оцінена оптична нелінійність другого порядку для $\mathrm{AgGaGeS}_{4}$ становить 5,79 пм/B.

(C) Мирончук Д.Б., студент., Кот Ю.О., студент, Мирончук Г.Л. к.ф.м.н., доц., Замуруєва

О.В., к.ф.-м.н. 
Згідно проведених експериментів та аналізу отриманих результатів видно, що інтенсивність ГДГ збільшується зі зменшенням ширини забороненої зони як для $\mathrm{AgGaGe}_{3} \mathrm{Se}_{8}$ $(2,2 \mathrm{eB})$ так і для $\mathrm{AgGaGeS}_{4}(2,8 \mathrm{eB})$, що є характерним для багатокомпонентних халькогенідних кристалів (Рис.3).

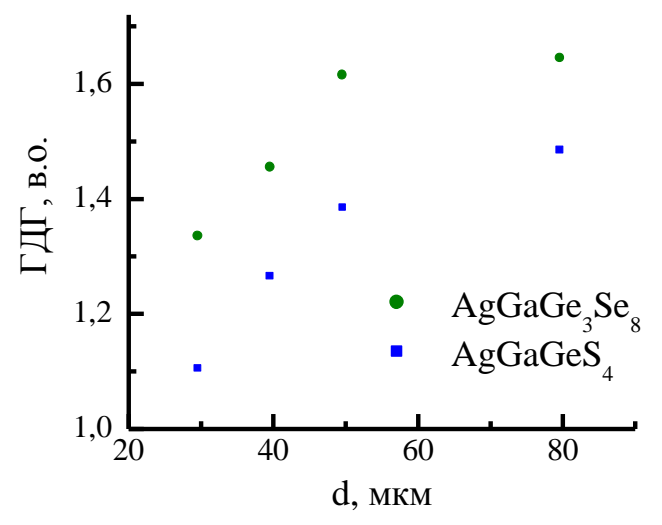

Рис.3. Залежність інтенсивності генерації другої гармоніки від середніх розмірів зерен кристалічного порошку

Ширина забороненої зони як для сульфідів, так і для селенідів є більшою, ніж для еталонних $\mathrm{AgGaS}_{2}(2,64 \mathrm{eB})$ та $\mathrm{AgGaSe}_{2}(1,8 \mathrm{eB})$. Через збільшення ширини забороненої зони ці сполуки можуть мати більші пороги лазерного пошкодження в порівнянні з еталонними. Разом із тим інтенсивність сигналу ГДГ для обох сульфідів порівняна $3 \mathrm{AgGaS}_{2}$, а селенідів $3 \mathrm{AgGaSe}_{2}$, що і визначає перспективність використання цих сполук.

Висновки. Отриманий результат свідчить про те, що багатокомпонентні халькогеніди, а саме $\mathrm{AgGaGeS}_{4}$ та $\mathrm{AgGaGe}_{3} \mathrm{Se}_{8}, €$ перспективними нелінійно-оптичними матеріалами, оскільки в них поріг лазерного пошкодження є більшим, а нелінійно-оптичний відгук порівняний із комерційно використовуваними $\mathrm{AgGaS}_{2}$ та $\mathrm{AgGaSe}_{2}$.

Досягнуті параметри нелінійно-оптичних ефектів другого порядку, отриманих для довжин хвиль, відповідних освітленню ІЧ лазером, дає змогу прогнозувати широке застосування досліджуваних кристалів як матеріалів для нелінійно-оптичного перетворення ІЧ лазерних променів, що має вирішальне значення для ІЧ лідарних систем (світлові далекоміри). Потрібно зазначити, що впродовж кількакратної ІЧ-індукованої обробки, спостережувані фотоіндуковані зміни були повністю зворотними, що підтверджує їхній високий потенціал відтворення.

\section{Інформаційні джерела}

1. Филимонов А.А., Суров В.., Рез И.С. - ЖЭЕФ, 56, 1519 (1969)

2. Graja A., Phys.stat.sol., 27. 93 (1968): Acta.Phys.Polon., 26, 283 (1969)

3. Kurtz S. K., Perry T. T. A powder technique for the evaluation of nonlinear optical materials. J. Appl. Phys. 1968. Vol. 39. P. 3798-3813.

4. Isaenko L. I., Yelisseyev A. P. Recent studies of nonlinear chalcogenide crystals for the midIR. Semicond. Sci. Technol. 2016. Vol. 31. P. 123001 (24pp).

5. Kui $\mathrm{Wu}$, Shilie Pan. A review on structure-performance relationship toward the optimal design of infrared nonlinear optical materials with balanced performances / Coord. Chem. Rev. 2018. Vol. 377. P 191-208.

6. Fei Liang, Lei Kang, Zheshuai Lin, and Yicheng Wu. Mid-infrared nonlinear optical materials based on metal chalcogenides: structure-property relationship. Cryst. Growth Des. 2017. Vol. 17, № 4. P. 2254-2289.

7. Silver thiogallate, a new material with potential for infrared devices / D. S. Chemla, P. J. Kupecek, D. S. Robertson, R. C. Smith. Opt. Commun. 1971. Vol. 3. P. 29-31.

8. Boyd G. D., Buehler E., Storz F. G. Linear and nonlinear optical properties of $\mathrm{ZnGeP}_{2}$ and CdSe. Appl. Phys. Lett. 1971. Vol. 18. P. 301-304.

9. Mechanism of linear and nonlinear optical effects of chalcopyrite $\mathrm{AgGaX}_{2}(\mathrm{X}=\mathrm{S}, \mathrm{Se}$, and Te) crystals / L. Bai, Z. Lin, Z.Wang, C.Chen, M. H. Lee. J. Chem. Phys. 2004. Vol. 120. P. 8772-8778.

(C) Мирончук Д.Б., студент., Кот Ю.О., студент, Мирончук Г.Л. к.ф.м.Н., доц., Замуруєва

О.В., к.ф.-м.н. 
10. Orthorhombic nonlinear crystals of $\mathrm{Ag}_{\mathrm{x}} \mathrm{Ga}_{\mathrm{x}} \mathrm{Ge}_{1-\mathrm{x}} \mathrm{Se}_{2}$ for the mid-infrared spectral range / Valeriy Badikov, Konstantin Mitin, Frank Noack, Vladimir Panyutin, Valentin Petrov, Alexander Seryogin, Galina Shevyrdyaeva. Opt. Mater. 2009 Vol. 31, № 4. P. 590-597.

11. Orthorhombic nonlinear crystals of $\mathrm{Ag}_{\mathrm{x}} \mathrm{Ga}_{\mathrm{x}} \mathrm{Ge}_{1-\mathrm{x}} \mathrm{Se}_{2}$ for the mid-infrared spectral range / V. Badikov, K. Mitin, F. Noack, V. Panyutin, V. Petrov, A. Seryogin and G. Shevyrdyaeva. Opt. Mater. 2009. Vol. 31, № 4. P. 590-597. 2005.

12. Nonlinear optical crystals: A complete survey / ed. D. N. Nikogosyan. New York: Springer,

Мирончук Д.Б., студент., Кот Ю.О., студент, Мирончук Г.Л. к.ф.м.н., доц., Замуруева О.В. к.ф.-м.н., ст.викл.

Восточноевропейский национальный университет имени Леси Украинки

ВЛИЯНИЕ РАЗМЕРА ЗЕРЕН КРИСТАЛЛИЧЕСКОГО ПОРОШКА НА ИНТЕНСИВНОСТЬ ГЕНЕРАЦИИ ВТОРОЙ ГАРМОНИКИ

В данной работе проведен анализ влияния ширины запрещенной зоны и средних размеров зерен на интенсивность генерации второй гармоники кристаллов $\mathrm{AgGaGeS_{4 }}$ и $\mathrm{AgGaGe} \mathrm{Se}_{8}$. Полученный результат свидетельствует о том, что многокомпонентные халькогениды, а именно $\mathrm{AgGaGeS} 4$ и $\mathrm{AgGaGe} \mathrm{Se}_{8}$, являются перспективными нелинейнооптическими материалами, поскольку в них порог лазерного повреждения является большим, а нелинейно-оптический отклик сравним с коммерчески используемыли $\mathrm{AgGaS}$ и $\mathrm{AgGaSe}_{2}$.

Ключевые слова: нелинейная оптика, лазер, генераџия третьей гармоники.

Myronchuk D. B., student., Kot Yu.O, student, Myronchuk, G.L. Ph.D., Assoc. Zamurujeva O.V. Cand. Sc. (Phys.-Math.)

Lesya Ukrainka Eastern European National University

\section{INFLUENCE OF THE SIZE OF CRYSTALLINE POWDER GRAINS ON THE} INTENSITY OF GENERATION OF SECOND HARMONICS

In this paper, we analyzed the influence of the band gap and the average grain size on the intensity of generation of the second harmonic of $\mathrm{AgGaGeS} \mathrm{S}_{4}$ and $\mathrm{AgGaGe} \mathrm{Se}_{8}$ crystals. The result suggests that multicomponent chalcogenides, namely $\mathrm{AgGaGeS}{ }_{4}$ and $\mathrm{AgGaGe}{ }_{3} \mathrm{Se}_{8}$, are promising nonlinear-optical materials, since the laser damage threshold is large and the nonlinear-optical response is comparable to the commercially used $\mathrm{AgGaS}$ and $\mathrm{AgGaSe}$.

Keywords: nonlinear optics, laser, third harmonic generation

(С) Мирончук Д.Б., студент., Кот Ю.О., студент, Мирончук Г.Л. к.ф.м.н., доц., Замуруєва

О.В., к.ф.-м.н. 